\title{
The Residency Advisory Committee: Steering Pharmacy Postgraduate Training
}

\section{Razan M El Melik ${ }^{1}$, Wesam W Ismail ${ }^{2 *}$, Esraa I Khader ${ }^{2}$, Nabil Khalidi $^{3}$, Shmeylan Alharbi ${ }^{4}$, Abdulmalik M Alkatheri ${ }^{5}$, Abdulkareem M Albekairy $^{6}$ and Saleh Aldekhael ${ }^{7}$}

${ }^{1}$ Assistant Professor, Pharmacy Practice Department, College of Pharmacy, King Saud bin Abdulaziz University for Health Sciences (KSAU-HS) and Clinical Pharmacist - Internal Medicine, King Abdulaziz Medical City, Saudi Arabia ${ }^{2}$ Lecturer, Pharmacy Practice Department, College of Pharmacy, King Saud bin Abdulaziz University for Health Sciences (KSAU-HS), Saudi Arabia

${ }^{3}$ Professor, Pharmacy Practice Department, College of Pharmacy, KSAU-HS, Saudi Arabia and Clinical Associate Professor Emeritus, College of Pharmacy, University of Michigan, USA

${ }^{4}$ Program Director, Pharmacy Residency, King Abdulaziz Medical City, ConsultantClinical Pharmacist, King Abdulaziz Medical City, Associate Professor, Pharmacy Practice Department, College of Pharmacy, KSAU-HS, Saudi Arabia ${ }^{5}$ Assistant Vice President, Educational Affairs, KSAU-HS, Professor, Pharmacy Practice Department, College of Pharmacy, KSAU-HS, Consultant-Clinical Pharmacist, King Abdulaziz Medical City, Saudi Arabia ${ }^{6}$ Assistant Director, Clinical Pharmacy Services, King Abdulaziz Medical City, Dean, College of Pharmacy, KSAU-HS and Associate Professor, Pharmacy Practice Department, College of Pharmacy, KSAU-HS and Consultant-Clinical Pharmacist, King Abdulaziz Medical City, Saudi Arabia

${ }^{7}$ Director, Pharmaceutical Care Services, King Abdulaziz Medical City, Assistant Professor, Pharmacy Practice Department, College of Pharmacy, KSAU-HS, Saudi Arabia

*Corresponding Author: Wesam W Ismail, Lecturer, Pharmacy Practice Department, College of Pharmacy, King Saud bin Abdulaziz University for Health Sciences (KSAU-HS), Saudi Arabia.
Received: September 18, 2020

Published: October 16, 2020

(C) All rights are reserved by El Melik RM., et al.

\footnotetext{
Abstract

Purpose: To describe the structure and functions of a pharmacy residency advisory committee (RAC) that manages the postgraduate years 1 and 2 programs in a large teaching institution.

Summary: Residency programs are faced with increasing number of residents and expanding specialty programs that increase the complexity of managing the diverse residency programs and require additional time commitments in order to maintain high quality learning, practice. Therefore, residency programs require a focused and centralized approach via the establishment of a pharmacy residency committee that oversees the residency programs and steers them in the right direction. Under the direction of RAC, collaborative approach between pharmacy staff, clinicians, faculty, and managers is essential to the successful management of the staffing, clinical, academic, and professional development of pharmacy residents.

Conclusion: Pharmacy residency programs in Saudi Arabia can be successfully managed by the coordination of efforts between preceptors and residents under the oversight of RAC.

Keywords: International Pharmacy Residency; King Abdulaziz Medical City; PGY1 Pharmacy Residency; Pharmacy Residency Advisory Committee; RAC; Saudi Arabia
} 


\section{Introduction}

With the steady growth and expansion of pharmacy residency programs to accommodate more postgraduate years 1 and 2 (PGY1 and PGY2) residents, pharmacy departments are faced with the challenges of managing a larger number of residents while providing quality training and educational experiences $[1,2]$. For accreditation purposes, the American Society of Health-System Pharmacists (ASHP) reviews the PGY1 and PGY2 residency programs separately and does not require the coordination of approaches and efforts to simultaneously manage all residency programs within a training site. Although ASHP has set specific standards, outcomes, goals, and objectives for PGY1 and each PGY2 programs, its regulations and standards for residency program accreditation are similar for training and practice sites, pharmacy services, residents' evaluation and mentoring, and preceptors' development and evaluations [3]. Typically, PGY2 specialty programs are individually managed by a residency program director (RPD), but the crisscross of several residency learning and practice requirements between PGY1 and PGY2 programs benefit from a collective approach to the management of all residency programs combined. This can be best achieved by establishing a residency advisory committee (RAC) that steers the residency programs in the direction of meeting the desired goals and objectives. This paper describes the role, structure and functions of RAC based on accumulated experiences with pharmacy residency programs at King Abdulaziz Medical City.

The need for a structured approach in managing pharmacy residency programs

In a 2004 survey of US academic medical centers that represented about $60 \%$ of residency positions offered by the University Health System Consortium (UHC) member hospitals, it was revealed that the most challenging issues to residency programs were the compliance with the evaluation and documentation elements of the ASHP Residency Learning System (RLS), resident recruitment, and research requirements [4]. Although the prevalence and complexity of issues vary between programs, these results highlight the need for a structured approach and collaborative efforts to manage residency programs.

Little information is available describing the structure and functions of a pharmacy residency committee, but more information can be found in the literature describing medical residency training committees [5-8]. In one report, the main roles of a medical residency committee that consisted of 23 medical faculty and house staff was focused on residents' education, evaluation, and development. Despite the relatively large number of committee members and delegation of workload to subcommittees, the main issue reported was the extensive time commitment to managing the residency program [8]. In another report that evaluated the administrative structure and workload of residency program committees for the Canadian psychiatry residency programs, the responsibilities of the residency committee included curriculum development, research, mentorship, program accreditation, setting the residents rotations, promoting the program, and fellowship programs. However, there was a disproportionate distribution of the workload between residency program directors and residency committee members who did not have significant involvement in the decision making and program development. The residency program directors spent $37 \%$ of their time for managing $82 \%$ of the committee workload [9]. Therefore, workload restructuring was essential in that program for sharing responsibilities and equitable work distribution amongst committee members [5].

Pharmacy residency programs in Saudi Arabia and the role of Saudi commission for health specialties

In 1997, King Faisal Specialist Hospital and Research Center (KFSH\&RC) in Riyadh, was the first to establish a one-year postgraduate pharmacy residency program in affiliation with St. Louis College of Pharmacy in St. Louis, Missouri USA [10]. The main purpose of the residency program was to provide pharmacists an opportunity to gain local and international clinical experience. In 2001, a full-fledged two years residency program was started under the governance of the Saudi Commission for Health Specialties (SCFHS) with the expansion of program sites to major Saudi cities such as in Jeddah and Riyadh. In the absence of an ACPE accredited Doctor of Pharmacy (PharmD) program in Saudi Arabia, the pharmacy residency postgraduate year 1 (PGY 1) expanded to two years in comparison to one-year PGY1 programs in the United States. The first year focuses on hospital pharmacy training, and second year focuses on clinical training. Then in 2012, SCFHS approved addition of a third year specialized residency to resemble PGY2 residency programs in the United States. King Abdulaziz Medical City (KAMC) offers two years of PGY1 and one year of PGY2. Current PGY2 specialties include nephrology, organ transplant, critical care, cardiology, oncology, and pediatrics.

Currently there are twenty SCFHS-accredited pharmacy residency programs in Saudi Arabia. In Riyadh, there are several pro-

Citation: El Melik RM., et al. "The Residency Advisory Committee: Steering Pharmacy Postgraduate Training”. Acta Scientific Pharmaceutical Sciences 4.11 (2020): 72-76. 
gram sites including: King Abdulaziz Medical City, King Fahad Medical City, King Faisal Specialist Hospital and Research Center, King Khalid Eye Specialist Hospital, King Khalid University Hospital, King Saud Medical City, Prince Mohammed bin Abdulaziz Hospital, Prince Sultan Cardiac Center, Prince Sultan Military Medical City, and Security Forces Hospital.

Of the twenty SCFHS-accredited pharmacy residency programs; only five PGY1 programs and two PGY2 specialty programs are ASHP-accredited.

In Saudi Arabia, SCFHS regulates health related training and licenses health care providers. Under the umbrella of SCFHS, Saudi pharmacy board is responsible for pharmacy residency programs. Saudi Pharmacy board consists of pharmacy residency central committee, exam/acceptance committee, site accreditation committee, and program accreditation committee.

The pharmacy residency central committee is chaired by a pharmacy board member and includes program directors of all training sites. The committee is responsible for reviewing residents' performance and progress. Exam/acceptance committee organizes all exams for residents for admission, promotion and final exit exam. Site accreditation committee assesses all training sites to ensure compliance with SCFHS accreditation requirements.

\section{King Abdulaziz Medical City - Riyadh}

King Abdulaziz Medical City in Riyadh is a 1256 bed teaching tertiary center that commenced operation in 1983. It is one of the five medical sites of the Ministry of National Guard - Health Affairs (MNGHA) that are spread across the regions of Saudi Arabia. The hospital has been fully accredited by the Joint Commission International (JCI) since 2006. The facility provides a variety of care, which includes Cardiac and Liver Transplant Center, Adult ICU, Trauma Center, Pediatric and Neonatal ICUs, Ambulatory Care, home healthcare services, and King Abdullah International Medical Research Center. The Medical Center is affiliated with King Saud bin Abdulaziz University for Health Sciences.

\section{Pharmaceutical care department at King Abdulaziz Medical} City

The pharmaceutical care department at King Abdulaziz Medical City is a progressive modern department in its setup and operations. The department is fully computerized and operates on the unit dose distribution system via decentralized satellites system and IV admixture services, and eleven satellites of which seven in the inpatient area and four in the outpatient. The department of pharmaceutical care has a close formulary with an annual drug budget of $\$ 114 \mathrm{M}$. Total of 42 clinical pharmacists, 16 are clinical pharmacists, 8 are clinical pharmacy specialists, and 18 are associate clinical pharmacists.

Pharmacy residency program at King Abdulaziz Medical City, Riyadh

In 2001, two years pharmacy practice residency program which is equivalent to PGY 1 was initiated. It was accredited by the official local accreditation body for health training; the Saudi Commission for Health Specialties. In September 2014 the program got the international accreditation by ASHP [3]. The purpose of the program is to prepare the pharmacist to be an excellent clinician for patient care positions, obtain a faculty position, or enter into PGY2 training in the area of choice.

\section{RAC structure}

RAC structure consists of six voting members that include the residency program director (RPD), pharmaceutical care services director, assistant director for clinical services, clinical preceptors' representative, staff development coordinator, and a secretary. The RAC is chaired by the RPD and meets quarterly to review and discuss the progress of the residents. Interactive feedback within the committee is utilized to direct the residents in their current and upcoming residency activities, and to provide mentoring/guidance. RAC members are selected based on clinical competence, scholastic achievements, and a history of proven ability to teach and mentor residents and pharmacy students. All members are appointed to staggered terms by the residency program director with the endorsement of the director of the Medical Education per King Abdulaziz Medical City hospital policies and regulations.

\section{RAC functions and responsibilities}

RAC has the delegated responsibility for residents' education, learning, and practice activities. It sets and defines the strategy, philosophy, and actions of the residency programs in accordance to established criteria by the Department of Pharmacy and ASHP and provides oversight for the management of the PGY1 residency program. RAC maintains a residency manual that is regularly updated and includes the policies, procedures, forms, and process description of the residency programs. RAC responsibilities are: 
- $\quad$ Overseeing PGY1 residency program activities by ensuring continuous residency programs accreditation status.

- $\quad$ Promoting the residency programs by planning events for ASHP-midyear showcase, local showcases, local colleges' career fairs, and other residency professional meetings.

- $\quad$ Selecting, interviewing, and recruiting residency candidates.

- $\quad$ Criteria-driven guidelines are used for the evaluation, selection, and ranking of residency applicants and candidates.

- $\quad$ Ensuring residents licensure and certification in accordance to Saudi Arabia's laws and institutional regulations.

- Regularly reviewing the quality of the residency training sites; competency of preceptors; rotations goals, objectives and practice foundations skills according to the RLS; and residents' progress towards achieving the residency goals and objectives.

- $\quad$ Setting the calendar and time schedule for residency activities (e.g., orientation, projects and evaluations deadlines; projects presentations; didactic teaching), setting the format and requirements for the residents' research and writing projects (e.g., project feasibility and eligibility, responsibility of residents and advisors).

- $\quad$ Reviewing and approving the residents' research and writing projects proposals, developing criteria for the equivalent experiences, core and elective rotations, longitudinal rotations, qualifications of preceptors, and minimum daily contact hours between preceptors and residents, ensuring timely completion of evaluations (e.g., resident baseline self-assessment, quarterly report, and individualized action plan; monthly and longitudinal rotations evaluations; seminar evaluations).

- $\quad$ Reviewing and approving the residents' research and writing projects proposals, developing criteria for the equivalent experiences, core and elective rotations, longitudinal rotations, qualifications of preceptors, and minimum daily contact hours between preceptors and residents, ensuring timely completion of evaluations (e.g., resident baseline self-assessment, quarterly report, and individualized action plan; monthly and longitudinal rotations evaluations; seminar evaluations).

- Addressing residency related conflicts and issues, facilitating the resident's involvement with internal, local, regional, and national committees, supporting and approving residents' business travel, conference attendance, vacation, and personal leaves.
- $\quad$ Facilitating the presentation of the research data at regional and national meetings, providing mentorship to residents, reviewing the qualifications and approving the nominees and elected Chief residents, ensuring completion of all residency requirements, deciding on residents' dismissal, and approving residents' graduation, and ensuring the resident's meet RAC expectations.

\section{RAC key features}

While managing each residency program varies between institutions, some distinct RAC features are worth highlighting like: RAC meetings, retreat, annual calendar, preceptors meetings, mentorship, and exit interviews.

Regular standing RAC meetings are scheduled quarterly. This allows the continuous and close assessment of the residents and residency programs and addresses any emergent issues in a timely manner. No cancellation of two RAC meetings in a sequence allowed in order to avoid any gaps in fulfilling RAC's roles in managing the residency programs and attending to the residents' needs.

A RAC retreat is planned to be implemented and will be scheduled annually. It will include RAC members, faculty, preceptors, and selected managers. RAC retreat is aimed at discussing residencyrelated issues and reviewing residency policies and processes that require extensive deliberations. It will discuss comments by graduating residents made during the formal individual exit interview with the RPD.

An annual calendar of residency activities is disseminated outlining deadlines and a series of pre-deadline dates commensurate with a project progression. At the beginning of the residency year, a calendar of events, deadlines, and alert dates is provided to the residents in order to help the residents with proactive planning, prioritization of responsibilities, and timely achievement of the residency goals and objectives. As an example, the research project is divided into subset of processes that each has its own guiding timelines from start to completion, beginning with the selection of topic, literature review, proposal submission, proposal presentation, data analysis, final presentation, and submission of final report.

A preceptor meeting is also annually and is held in order to provide preceptors with residency updates and promote collective discussions of residency matters amongst preceptors.

Citation: El Melik RM., et al. "The Residency Advisory Committee: Steering Pharmacy Postgraduate Training". Acta Scientific Pharmaceutical Sciences 4.11 (2020): 72-76. 
In addition, RAC mandates that every resident has assigned mentors who meet regularly with the resident to continuously evaluate the resident's progress throughout the residency program, provide personal and professional developmental support and career advice, and assist in any conflict resolution. When necessary, RAC intervenes to provide guidance or corrective action plan.

Finally, the RAC program director conducts individual exit interviews with graduating residents at the end of the residency year. The interviews gather confidential feedback from the residents in order to help identify any residency-related issues or suggestions as part of the continuous quality assessment of the residency programs.

\section{Challenges to the residency program}

Managing residency programs presents with complex issues. Based on experiences from King Abdulaziz Medical City, some of the key challenges include:

- Balancing residency expectations and requirements with residents' capacities, background, and capability.

- Keeping the scope, quality, and expectations of residents' training consistently above those of PharmD clerkship students.

- Time commitment of RAC members to the residency programs.

RAC has in the past mentored a local residency program's leadership preparing the program for ASHP residency accreditation as part of its mission and has nurtured the development of a residency training program at an international site.

\section{Conclusion}

The number of pharmacy residency programs is increasing in Saudi Arabia. Therefore, a well-structured residency advisory committee (RAC) seems to be the optimal approach to the ideal planning, conducting and continuously improving PGY1 and PGY2 residency programs that meet the accreditation standards and their intentions. Implementing RAC will help overcome most of the major challenges to managing residency programs mentioned above as well. More importantly, it fulfills the aspiration of both the program's residents and their preceptors.

\section{Conflict of Interest}

Authors reported none.

\section{Bibliography}

1. Talley CR. "Growth in Pharmacy Residency Training". American Journal of Health-System Pharmacy 63.7 (2006): 619.

2. Teeters JL., et al. "Pharmacy Residency Training in the Future: A Stakeholder's Roundtable Discussion". American Journal of Health-System Pharmacy 62.17 (2005): 1817-1820.

3. American Society of Health-System Pharmacists. "Ashp Regulations on Accreditation of Pharmacy Residencies". (2015).

4. Hoffman JM., et al. "Pharmacy Residency Training in Academic Medical Centers". American Journal of Health-System Pharmacy 61.23 (2004): 2528-2533.

5. van Zyl LT and PR Davidson. "Canadian Psychiatry Residency Training Programs: A Glance at the Management Structure". The Canadian Journal of Psychiatry (2006).

6. Beresin EV. "The Administration of Residency Training Programs". Child and Adolescent Psychiatric Clinics of North America 11.1 (2002): 67-89.

7. Durning SJ., et al. "A Resident Research Director Can Improve Internal Medicine Resident Research Productivity". Teaching and Learning in Medicine 16.3 (2004): 279-283.

8. Lovejoy FH., et al. "Ten Years of a Residency Training Committee". Acadamic Medicine 66.10 (1991): 602-603.

9. van Zyl L T., et al. "Administrative Restructuring of a Residency Training Program for Improved Efficiency and Output". Acadamic Psychiatry 29.5 (2005): 464-470.

10. Al-Qadheeb NS., et al. "The First International Residency Program Accredited by the American Society of Health-System Pharmacists". American Journal of Pharmaceutical Education 76 (2012): 1553-6467.

\section{Assets from publication with us}

- Prompt Acknowledgement after receiving the article

- Thorough Double blinded peer review

- Rapid Publication

- Issue of Publication Certificate

- High visibility of your Published work

Website: www.actascientific.com/

Submit Article: www.actascientific.com/submission.php

Email us: editor@actascientific.com

Contact us: +919182824667

Citation: El Melik RM., et al. "The Residency Advisory Committee: Steering Pharmacy Postgraduate Training”. Acta Scientific Pharmaceutical Sciences 4.11 (2020): 72-76. 